\title{
El Nobel olvidado: algunas notas sobre la contribución de Carl Spitteler a la evolución de la narrativa suiza en el siglo XX
}

Isabel Hernández*

\begin{abstract}
This paper examines the decisive importance which the work of Switzerland's only - albeit now completely forgotten - Nobel Prize winner for Literature had on the development of Swiss prose in the 20th century, and all this without receiving any critical attention whatsoever. The article will also try to give an answer to one of the most frequently asked questions: why such a prestigious award was granted to an author whose name has not managed to travel beyond the borders of Switzerland or the limits of his lifetime.
\end{abstract}

Keywords: Swiss literature; Fin de Siècle; Prose; Literary engagement; Pacifism.

Zusammenfassung: Die vorliegende Arbeit versucht herauszuarbeiten, dass das Werk des einzigen, heute völlig vergessenen Schweizer Literaturnobelpreisträgers eine entscheidende Rolle für die Herausbildung der Schweizer Prosa des 20. Jahrhunderts gespielt hat, ohne dass die literarische Kritik dies in irgendeiner Weise zur Kenntnis genommen hätte. Andererseits wird auch versucht, eine sehr oft gestellte Frage zu beantworten: Warum ein so wichtiger Preis an einen Schriftsteller verliehen wurde, dessen Werk es nicht gelungen ist, eine deutliche Wirkung über die Grenzen der Schweiz und die seiner Zeit hinaus zu entfalten.

La autora es profesora titular de literatura alemana en la Universidad Complutense de Madrid. 
Stichwörter: Schweizer Literatur; Jahrhundertwende; Prosa; Engagement; Pazifismus.

Resumen: El presente artículo trata de poner de manifiesto cómo la obra del único Premio Nobel de las letras suizas, hoy en día completamente olvidado, ha tenido una importancia singular para la configuración de la narrativa suiza de épocas posteriores, sin que la crítica literaria haya sido ni sea consciente de ello. Asimismo trata de dar respuesta a algunos de los interrogantes más frecuentes respecto del porqué de la concesión de tan importante galardón a un autor que no ha conseguido traspasar las fronteras de la Confederación Helvética, ni tampoco las de su propia época.

Palabras-clave: Literatura suiza; Fin de siglo; Narrativa; Compromiso social; Pacifismo.

Resumo: O presente artigo trata de expor como a obra do único Prêmio Nobel das letras suíças, hoje completamente esquecido, teve uma importância excepcional para a configuração da narrativa suíça nas épocas seguintes, sem que a crítica literária se conscientizasse disso. Por outro lado, se tenta dar uma resposta à pergunta freqüente, por que uma distinção tão importante foi concedida a um autor que não pôde ultrapassar as fronteiras da Confederação Helvética e da sua própria época.

Palavras-chave: Literatura suíça; Fim do século; Narrativa; Compromisso social; Pacifismo.

Si de entre los premios Nobel otorgados a escritores de lengua alemana hay alguno injustamente olvidado hoy en día, ése es, sin lugar a dudas, Carl Spitteler (1845-1924). Que la concesión del premio más importante donde los haya tuviera lugar precisamente en el año $1919^{1}$, esto es, en el año final

1 El premio se le entregó en realidad en 1920, pues la entrega de 1919 se pospuso debido a la situación internacional. Recibió, por tanto, el galardón a la vez que el noruego Knut Hamsun, aunque Spitteler aparece en el elenco de premiados correspondiente al año 1919. 
de la primera gran contienda bélica mundial, tiene seguramente mucho que ver con este olvido y con el escaso interés que la obra de un autor tan prolífico y polifacético ha despertado en los lectores de épocas posteriores ${ }^{2}$. No obstante, una atenta lectura de la obra de este escritor nos descubre en él no sólo al poeta interesado por la literatura clásica, al autor de las epopeyas configuradas sobre el trasfondo de la antigua Grecia, sino también al narrador, al novelista que supo ver los cambios radicales que estaban teniendo lugar en su entorno y recogerlos en unos textos que resultan básicos para comprender el devenir de la prosa suiza durante la primera mitad del siglo XX.

Que pueda afirmarse esto de la obra de Spitteler tiene mucho que ver con su propia biografía o, dicho de otro modo, con el hecho de que el autor vivió un momento histórico y literario que hizo de él el auténtico puente entre el siglo XIX y el XX, entre los géneros de la literatura regional y el realismo crítico, entre la epopeya y la prosa, entre el mito y la realidad. Y ello es así porque su obra literaria es tan heterogénea como su propia vida. Nacido en el seno de una distinguida familia, cuyas actividades en el ámbito social y comercial - su padre llegó a ocupar numerosos cargos políticos al margen de los cuales fue también un apreciado comerciante - marcaron decididamente la infancia y posterior evolución del futuro escritor, estudió Teología en Zúrich, Heidelberg y Basilea, tras lo cual se inició en el terreno literario con una finalidad muy concreta: dedicarse a todos los ámbitos de la literatura y buscar nuevas formas sin olvidar por ello la tradición. En este sentido es evidente la influencia de Gottfried Keller, Conrad Ferdinand Meyer y Jeremias Gotthelf en algunas de sus primeras obras como Das Wettasten von Heimligen (1890), Der Neffe des Herrn Bezenval (1889) o Friedli der Kolderi (1890) respectivamente, así como de la literatura regional en Gustav. Ein Idyll (1891), esta última una novela sacada de lo que, en principio, estaba

2 Como es evidente, uno de los momentos de mayor interés por la obra de Spitteler tuvo lugar al hilo de la concesión del premio. En los años posteriores, y también tras su fallecimiento en 1924, la crítica se interesó por comprender una obra que no resultaba en absoluto fácil, intentando acercarla a un público para el que el propio autor nunca pretendió tampoco escribir. El carácter elitista que él mismo quiso dar a su producción se mantuvo por tanto también en aquellos años, tal como continúa manteniéndose hoy. 
planeado como un ciclo sobre Heimligen, de similares características al de la Seldwyla de Keller. Tras estas primeras incursiones en el ámbito de la tradición suiza y de una temprana autobiografía, Meine frühesten Erlebnisse (1913), compuesta de forma poco convencional, puesto que en ella recoge recuerdos de sus tres primeros años de vida, abriendo con ello una vía para la reflexión psicológica, Spitteler se entusiasmó en las clases de su maestro Jakob Burckhardt por la Antigüedad Clásica, abandonando todos sus proyectos al tiempo que comenzaba a reivindicar la tragedia como única forma literaria posible. A este escrito autobiográfico le seguiría algunos años después el titulado Das entscheidende Jahr (1925). Ambos son básicos para la comprensión del conjunto de su producción, pues en los dos se describe la relación del joven y del adulto con el mito, siempre a través de las propias experiencias vividas.

Pero sus comienzos literarios no fueron precisamente fáciles, debido a la presión que su padre ejercía sobre él para que se dedicase a una profesión que le diera prestigio social ${ }^{3}$. Es probable que esta presión le hiciera enfermar y experimentar una primera crisis vital, tras la cual, apenas recuperado, sufriría una pronta recaída al prometerse su amigo, el también escritor Josef Viktor Widmann (1842-1911), con su joven tía, Sophie Brodbeck, recién enviudada, nueve años mayor que él, pero de la que estaba secretamente enamorado. En ese estado de dolorosa crisis, Spitteler vio de repente cómo todos sus amigos cerraban un círculo del que había quedado excluido y relegado, por tanto, a seguir su camino en solitario. Dada la situación, así como los

3 La relación con su padre, experimentada por Spitteler como una relación negativa, debido al carácter autoritario de aquél, es una constante que aparece de manera sistemática en un buen número de sus obras. Con frecuencia se ha establecido una estrecha relación entre novelas como Gustav o Conrad der Leutnant y la conocida Brief an den Vater de Franz Kafka. En su monografía sobre la narrativa de Spitteler, Luigi Quattrocchi dedica dos capítulos al análisis de este conflicto que marcó la biografía del autor de manera decisiva. Vid. QuATTROCCHI, Luigi (1968), 49-104: cap. III: Il rapporto padre-figlio: l' 'idillio' Gustav; cap. IV: Il rapporto padre-figlio: Conrad der Leutnant. Interesante es también su artículo "Il rapporto Padre-Figlio in Carl SpItTeLer: Conrad der Leutnant". En: CHIARINI, Paolo, Miscellanea di studi in onore di Bonaventura Tecchi, Roma, Edizioni dell'Ateneo 1969, 460-487. 
continuos enfrentamientos con su padre, decidió abandonar la casa paterna y, tras vagar durante un tiempo por el campo y las montañas, se estableció durante un año en casa de unos amigos en Lucerna. Allí no consiguió concentrarse ni terminar ninguna obra, por lo que finalmente acabó cediendo a los ruegos de su padre para que volviera a casa, pues ahora se conformaba tan sólo con que ejerciera un oficio, fuera del tipo que fuera. En los apuntes de esos años y en su autobiografía ha quedado constancia de las duras batallas internas que libró consigo mismo, pues, aun queriendo seguir por encima de todo sus propias inclinaciones, también deseaba por otro lado cumplir los deseos del padre consiguiendo un trabajo seguro; no obstante, la ordenación como prefecto de la parroquia de Langwies hizo que volvieran a surgir en su cabeza toda una serie de dudas y luchas internas, por lo que no vaciló en aceptar la oferta de un amigo de la familia para trasladarse a San Petersburgo a casa del general Standertskjöld primero y a la de Von Cramer después para trabajar allí como preceptor. Durante esos ocho años, de 1871 a 1879, Spitteler viajó mucho: de Moscú a París, de Suecia al sur de Italia, llegando a conocer bastante bien diversos países de Europa, sobre todo la zona del Báltico. Este periodo de constantes viajes continúa siendo incluso hoy en día un enigma en la biografía del autor, pero si se interpreta en relación con el conjunto de su obra, tal vez pueda entenderse como una huida que él consideraba sin duda necesaria para preservar la propia libertad frente a las imposiciones paternas. Sus impresiones de estos años están recogidas en las narraciones Ei Ole (1887) y Das Bombardement von Abo (1889). En cualquier caso, y aunque a los dieciocho años, Spitteler ya había leído a Ariosto y había despertado en él el deseo de dedicarse a la literatura, fue precisamente a lo largo de estos viajes cuando la lectura de los clásicos y de los estudios de Jakob Burckhardt sobre el Renacimiento que le acompañaron durante esta época le convencieron de la necesidad de escribir únicamente en esa línea, de la que surgirían sus grandes epopeyas en verso.

En 1879, a su regreso a Berna tras la muerte de su padre, dio clases durante un año en una escuela de señoritas, la Einwohnermädchenschule. Allí volvió a ver a la joven Ellen Brodbeck, a la que conocía desde niña, pues era hija del primer matrimonio de Sophie con su tío; su belleza le sobrecogió, pero cuando decidió declararle su amor, ella ya se había prometido con Ferdinand Vetter, once años mayor que ella y profesor de lite- 
ratura alemana en la Universidad de Berna. Los años que siguieron fueron difíciles: continuó dando clases en diferentes ciudades y poco a poco fue perfilando su obra literaria. Tan sólo el amor y la comprensión de su madre y de su amigo Widmann le mantuvieron a flote en medio de la dificultad. Pero tampoco el amor de una mujer tardaría en hacer aparición en su vida, pues muy pronto se enamoró de una de sus alumnas de Berna, Marie op den Hooff, con la que contrajo matrimonio en 1883 y tuvo dos hijas. Por otro lado, la herencia paterna le permitió desde entonces dedicarse exclusivamente a su producción literaria hasta su muerte en 1924, tras haber vivido los horrores y la locura de la guerra. Spitteler no fue nunca un escritor interesado por cuestiones políticas. Sin embargo, el 14 de diciembre de 1914, aterrorizado por la situación, pronunció en Zúrich por invitación de la Neue Helvetische Gesellschaft el que con el tiempo se convertiría en su discurso más famoso y por el que, en realidad llegaría a ser más conocido que por toda su producción literaria ${ }^{4}$, el titulado Unser Schweizer Standpunkt. En él, Spitteler criticaba el partidismo de los suizos germanófonos y francófonos a favor de los países vecinos, exigiendo además, de manera decidida, que los suizos permanecieran neutrales sin albergar ningún tipo de sentimiento hacia un conflicto que debía serles ajeno, lo cual contribuyó de manera decisiva a reafirmar "el foso" abierto entre ambas partes del país. Por otro lado, tomaba partido también a favor de las pequeñas naciones ocupadas por las tropas alemanas, como era el caso de Serbia y Bélgica,

4 Téngase en cuenta que precisamente este discurso le cerró para siempre las puertas del mercado editorial alemán, puesto que en él condenaba abiertamente el espíritu de la Alemania guillermina. Jost Hermand describe la situación de Spitteler en Alemania en relación con la novela Imago: "Man fragt sich, warum Spittelers Imago trotzdem so unbekannt geblieben ist, vielleicht hängt es mit dem Problem der deutschen Sonderfälle zusammen. Immer wieder entstehen in Deutschland bewußt oder unwillkürlich Einzelleistungen, die der Zeit vorauseilen. Aber sie bleiben unbekannt, weil sie nicht die Weite haben, wie die westeuropäisch-repräsentativen Werke. Sie sind enger, haben keinen gesellschaftlichen Ton, sind dafür aber manchmal unergründlich im einzelnen. Das hängt mit der eingekapselten Situation ihrer Autoren zusammen, die in sich befangen bleiben und denen oft altertümliche Reste anhaften". Hermand, Jost, "Spittelers Imago", Germanisch-Romanische Monatsschrift 5 (1955), 234. 
para intentar mantener la cohesión nacional. Este testimonio de pacifismo, esta llamada decidida a la salvaguarda de la libertad del individuo a todos los niveles en un momento tan crítico - según Spitteler tan sólo la libertad y la unidad serían capaces de proteger a la Confederación frente al peligro que la amenazaba, dado que sin libertad del pueblo no había libertad individual, al igual que sin libertad individual tampoco había libertad de actuación -, desempeñó un papel fundamental en la concesión del Premio Nobel a Spitteler, otra de las muchas cuestiones que tampoco se han estudiado a fondo dentro del conjunto de su obra, la cual puede analizarse en realidad como un todo unitario que mantiene de principio a fin unas constantes bien definidas, entre las cuales se encuentra la de la necesidad de vivir en un mundo armónico y en paz. De este modo, los protagonistas de sus obras se caracterizan uno tras otro por esa cualidad poco propia del individuo contemporáneo, que lo lleva a dar testimonio de su grandeza en acciones que bien podrían denominarse como heroicas, encaminadas todas ellas hacia la consecución de esa finalidad de vida armónica y en paz. Un buen ejemplo de esta actitud es, sin ir más lejos, Prometeo, el protagonista de su famosa epopeya Prometheus und Epimetheus, quien, al igual que el resto de los protagonistas de sus obras, es una metáfora del valor, del individuo que no tiene miedo a nada, que dice lo que ha de decir y que hace lo que ha de hacer en cada momento, sin temor a represalias, guiándose simplemente por su sentido de la justicia, un individuo que sufre en sus propias carnes un castigo inmerecido simplemente porque ha hecho algo en beneficio de los demás. Es de suponer, por tanto, que en la decisión de conceder el premio al escritor suizo pesara en buena medida su proyección internacional como pacifista en aquel momento, y que la Academia optara por subrayar la importancia de una obra de esas características con la concesión del galardón a un autor que no se encontraba, desde luego, entre los favoritos ${ }^{5}$.

Fue su amor por el mundo clásico el que le inspiró para componer su gran epopeya en cuatro tomos, Olympischer Frübling (1900) - la segunda

En cualquier caso, respecto del porqué de la concesión del Nobel a Spitteler pueden hallarse las explicaciones más diversas. Una de las más difundidas en los años inmediatamente posteriores fue la de que el francés Romain Rolland, 
versión de 1909 apareció ya reducida a dos - por la que la Academia justificó la concesión en 1919 del distinguido galardón. Escrita en hexámetros yámbicos rimados, los personajes de Spitteler en la mayoría de los casos sólo tienen en común con sus modelos griegos el nombre, y los acontecimientos que se relatan en ella no están relacionados con ninguna realidad histórica o social. Los personajes actúan en un espacio cósmico, aunque, al igual que en todas sus composiciones, se pueden ver destellos del paisaje de la zona sur del macizo del Jura, paisajes suizos, en definitiva, como en el resto de toda su obra. Entre la plenitud de episodios, historias y aventuras que se relatan destacan dos personalidades que se perfilan por encima de las demás: Zeus, que ejerce el poder con todos los medios a su alcance, aunque sean delictivos, y Apolo, representante de la belleza espiritual, quien, engañado por el primero, se ha retirado a un espacio macrocósmico. Es la dicotomía entre el bien y el mal, o llevado al terreno de la biografía del autor, entre las inclinaciones del artista y las imposiciones del orden social. No hay que olvidar que en su primera obra de tonos clásicos publicada con el pseudónimo de Carl Felix Tandem, Prometheus und Epimetheus. Ein Gleichnis (1880/1881), Spitteler se había enfrentado ya a través de la figura del titán a la problemática relación que se establece por lo común entre artista y sociedad, representada ésta por los deseos de su padre acerca de su futuro expuestos anteriormente. Spitteler había estado trabajando en ella durante más de trece años y, aun con todo, y a pesar de las muchas revisiones y reelaboraciones, se percibió en el momento de su publicación como un texto extraño, ajeno al gusto de la época, en el que dominaban las narraciones de tono realista, los idilios en verso y la literatura histórica de tono romántico y dramáti-

también Premio Nobel de Literatura en 1915, era en realidad el artífice de la concesión del premio debido a sus manifestaciones a favor del escritor suizo: "Der Nobelpreis für Literatur [...] war endlich eine weithin sichtbare Anerkennung des dichterischen Werkes: doch - man täusche sich nicht: die Ehrung war nicht getragen vom Urteil einer ganzen Nation [...]. Sie war der Erfolg eines einzelnen, hochgesinnten Mannes, der sich mit seiner ganzen gewichtigen Person in Stockholm für Spittelers Ehrung eingesetzt hatte; sie war der Erfolg und das Verdienst Romain Rollands". BuRTE, Hermann et al. (eds.), Carl Spitteler in Memoriam. Jena, Eugen Diederichs 1925, 26. 
$\mathrm{co}^{6}$. No resulta extraño, por tanto, que la crítica pasara por alto una obra, en la que su autor había querido reflejar toda una serie de sentimientos vitales bajo la máscara de las formas mitológicas y unos ritmos estrictos, poco frecuentes y apropiados para la prosa ${ }^{7}$. En ella Spitteler aúna de manera sincrética elementos de distintos ámbitos de la tradición; el núcleo lo constituye la saga griega de Prometeo: un solo individuo ayuda a los hombres en contra de los deseos de los dioses, llevando a cabo para ello una proeza, un hecho desacostumbrado: robar el fuego del cielo. En lugar de Zeus y el Olimpo, Spitteler describe aquí a un dios invisible, que se manifiesta en el

6 En este sentido debe tenerse en cuenta que el género que dominaba la prosa suiza en aquellos años era precisamente el del "Heimatroman": "Die Schweiz der raschen Industrialisierung, des expandierenden Fremdenverkehrs, des Alkohol- und Tuberkulosenproblems in den Vorstädten und verstädterten Landgemeinden, die Schweiz der Auswanderer und Söldner in fremden Diensten, der Verdingkinder und schlecht bezahlten Fabrik- und Büroarbeit, in der Literatur gab es sie nicht”. Pezold, Klaus (ed.), Geschichte der deutschsprachigen Schweizer Literatur im 20. Jahrbundert. Volk und Wissen, Berlin 1991, 14. Era, pues, una situación completamente diferente a la que se vivía en Alemania, donde el Realismo burgués había dejado paso al Naturalismo, mientras que en Suiza era el canon realista el que seguía marcando la pauta literaria. Evidentemente es posible encontrar algunas excepciones, como las narraciones de Carl Albrecht LoosLi, Der bureausaurus helveticus (1913), una crítica amarga a los oficinistas de finales de siglo, o William WoLFENSBERGER, Christus im Warenhaus (1917), una crítica de la sociedad de consumo, así como las obras de los autores que se agrupan hoy en día bajo el denominador de "década épica" -acuñado por Robert Walser-, los cuales viajaron con mucha frecuencia al extranjero y pasaron largas temporadas en los grandes centros de la cultura y la vida intelectual del momento, como París, Berlín o Múnich. Sólo ellos fueron capaces de poner de manifiesto a través de sus obras las grandes transformaciones que estaban teniendo lugar en la sociedad suiza, para lo que abandonaron definitivamente el género de la literatura regional. Entre ellos cabe destacar, además de los dos mencionados, a Albert Steffen (1884-1963), Jakob Schaffner (1875-1944), Paul Ilg (1875-1957), Charlot Strasser (1884-1950), y al propio Robert Walser (1878-1956).

7 Esta idea parece dominar todas las interpretaciones de las obras de Spitteler, que las definen como alegorías de difícil comprensión, hecho que, evidentemente, ha influido de manera decisiva en la escasa recepción de sus textos. 
ángel de Dios y en Doxa, la amiga y compañera del ángel, en la que se encarnan los elementos negativos. La obra tiene como protagonistas a dos hermanos de características opuestas: mientras Epimeteo es capaz de someterse a los dictados de las normas sociales que él ha interiorizado al formar su conciencia, el individutalista Prometeo sólo obedece a su propia moral. Cuando Epimeteo fracasa, dado que sus principios no le sirven de nada, y no es capaz de gobernar ni de defender su propio reino, Prometeo es el único capaz de intervenir para salvarlo, y ello a pesar de haberse opuesto a los planes de los dioses. Pasividad frente a actividad, por tanto, una dualidad que viene a demostrar lo novedoso de esta obra y, por ende también, del conjunto de la producción de Spitteler, pues se trata de la plasmación literaria de una dimensión psíquica no tenida en cuenta por los diferentes análisis que se han realizado de la obra, y que, sin embargo, sitúa al autor en la vanguardia del uso del análisis psicológico como recurso literario, ese elemento hoy en día tan característico de la literatura suiza en general. Spitteler no usa nunca los motivos de la mitología ni crea imágenes míticas arquetípicas para dar expresión a la grandeza dramática de estas tramas conocidas en buena medida por el público lector, sino que las utiliza como medios de expresión de toda una serie de profundas dimensiones psíquicas que el autor cree conveniente y necesario sacar a la luz. Ésta y no otra es la finalidad perseguida por el autor: el estilo es importante para él, pues, en su obsesión por ajustarse a los modelos clásicos, considerados como los únicos válidos para transmitir un mensaje literario, utiliza formas percibidas como extrañas por el lector de los años del cambio de siglo; pero lo que realmente resulta de una relevancia fundamental en sus obras es la forma de observar a sus personajes desde dentro, de realizar un análisis exhaustivo de los procesos mentales que experimentan sus protagonistas. Con ello, Spitteler se adelanta a su tiempo ${ }^{8}$ y aborda problemas y establece relaciones que a lo

8 Gottfried Keller supo ver antes que nadie la capacidad artística de Spitteler, así como su distanciamiento respecto de las tendencias del momento. De este modo lo expresó en una carta a su editor, Julius Rodenberg, fechada el 7 de diciembre de 1882: "Würde der Arme [Spitteler] sein Talent und seine starke Phantasie zur Gestaltung des wirklich dichterischen Menschlichen verwenden, so könnte er das Beste leisten”. KeLLER, Gottfried, Gesammelte Briefe in vier Bänden. Ed. de Carl Helbling. Benteli, Berna 1952, vol. 3,1, 402. 
largo del siglo XX serán objeto de estudio de la Psicología, así como temas de numerosas obras literarias?.

A pesar de ser su primera obra, se perciben en ella, no obstante, una serie de rasgos que aparecerán posteriormente en otros textos del autor. Ello puede deberse seguramente al hecho de que la trama de Prometeo fue para él una trama que le ocupó hasta el final de sus días, hasta el extremo de que, durante sus últimos quince años de vida, volvió a retomarla hasta conseguir darle una nueva forma en versos rimados en Prometheus der Dulder (1924): aquí, a pesar de las transformaciones propias del paso del tiempo, el ideario sigue siendo idéntico al que se reflejaba ya en la primera composición. Esto, evidentemente, es una buena muestra de que su producción literaria puede entenderse como un continum, es decir, como un todo que gira en torno al mismo tema, el cual se perfila a través de formas diferentes. No obstante, y a pesar de lo novedoso de este proyecto - la crítica lo denominaría hoy en día como un work in progress - es seguramente este hecho lo que en cierto modo provocó que, a pesar de su originalidad y de su carácter innovador, resultara en su época, y también hoy en día, algo fuera de contexto $^{10}$. Así pues, toda la obra de Spitteler gira en torno a una temática

9 Los personajes pesimistas de Spitteler, en los que es fácil reconocer rasgos propios del enfermo esquizofrénico o parafrénico, fueron objeto de análisis en prestigiosas revistas científicas, mientras que la crítica literaria no se hacía eco alguno de ellos. Los psicoanalistas tomaron incluso el título de una de sus novelas más famosas para bautizar con él una prestigiosa revista con sede editorial en Viena: Imago. Zeitschrift für die Anwendung der Psychoanalyse auf die Geisteswissenschaften.

10 Mi tesis de que tras esta falta de comprensión de los textos de Spitteler se esconde un proceso de elaboración literaria enormemente complejo se ve reforzada con las afirmaciones de Luigi Quattrocchi que califica el proceso creador del escritor suizo como un "sforzo costruttivo" (QuATTROCCHI (1968), 78), esto es, como la necesidad de liberarse del peso de la tradición de Keller y Meyer que se reflejaba en varias de sus obras, por un lado, y el "esfuerzo" por conseguir formas propias, adecuadas a cada temática en particular, sin perder por ello de vista el canon clásico: "E Spitteler riuscì davvero, e assai manifestamente a diversificarsi dall'uno e dall'altro [de Keller y de Meyer], sotto ogni rispetto, anche se l'originalità conseguita fu pagata al prezzo di una applicazione in alto grado attenta e disagevole, prezzo assai caro per uno scritto che non fuga, nel 
única, por lo que puede concluirse la existencia de un denominador común al conjunto de su producción: el motivo de la excepcionalidad, de la grandeza, su reconocimiento como peculiaridad que caracteriza a determinados individuos dentro del conjunto de la sociedad, y por la que han de pagar un precio muy doloroso. Un motivo por excelencia de la tragedia clásica, que muchos escritores de la primera mitad del siglo XIX retomaron también en sus obras, pues resultaba muy adecuado para dar expresión al genio del artista romántico. Este motivo se percibe con mucha claridad, por ejemplo, en Gustav. Ein Idyll: un joven artista, que no ha sido capaz de concluir los estudios de Medicina, tiene en una joven a la única persona que cree en su vocación. Sin que él se dé cuenta es ella la que le hace crecer y confiar en sus propias capacidades, renunciando a todo única y exclusivamente para que él pueda realizarse en la sociedad. De mucho más peso es, sin duda, la novela corta Die Mädchenfeinde (1907), debido a la capacidad descriptiva de que hace gala aquí el autor, a través de un triángulo de protagonistas - dos niños y una niña - que permite ver al lector las almas infantiles hasta el extremo de despertar auténtica admiración, así como también a la reconstrucción de unos paisajes idílicos en los que se insertan los personajes:

giudizio, varie e sostanziali perplessità, anzitutto circa la pertinenza della qualificazione di genere cui l'autore ritenne di poterlo affidare. Spitteler avrebbe cioè potuto limitarsi a una prova meno gravosa, ma non per questo meno produttiva, ché anzi è presumibile che avrebbe potuto meglio cimentarsi al di fuori di una pianificazione tanto 'voluta'; ma elesse la via fra tutte la più impervia, che fuori di ogni equivoco gli garantisse, e che in effetti gli consentì, una assai ampia reciproca adeguazione fra temi e mezzi espressivi prescelti. E gli uni e gli altri, in reciproco implicarsi, furono appunto tali, che una contaminazione con i moduli di Keller e di Meyer, i quali pur rimangono maestri ineguagliati, sarebbe stata senz'altro improponibile." QuatrRocchi, Luigi (1968), 81 ss. Yo añadiría, no obstante, un elemento más a esta teoría del "sforzo costruttivo": el hecho de que Spitteler era un gran conocedor de la literatura de su época -algo que se constata en sus observaciones sobre los más diversos autores y obras-, así como de la de épocas anteriores, entre las cuales trató siempre de buscar una posición intermedia que combinara forma "clásica" y contenido "actual". Spitteler era muy consciente de que los nuevos tiempos exigían nuevas formas, a la vez que lo era del enorme peso de los grandes realistas y del lastre con el que, debido a ello, cargaban los autores de su generación. 
inocencia y naturaleza se unen en las biografías de unos niños que, sin saberlo, pasarán rápidamente de la infancia a la adolescencia y, luego, al mundo de los adultos, con lo cual dejarán atrás para siempre el paraíso y el idilio de la infancia.

Dentro de sus composiciones narrativas, Spitteler practicó también el género de la novela corta de contenido social, como en Das Wettfasten von Heimligen (1890), y de contenido histórico en la titulada Der Neffe des Herrn Bezenval (1889). La primera se desarrolla en una pequeña comunidad - algo separada del curso del mundo siguiendo la línea de la Seldwyla de Keller -, utilizada por el autor como escenario en el que situar a unos personajes preocupados tan sólo de sus propios intereses, los cuales se constituyen, evidentemente, en objeto de una dura crítica social; la segunda tiene como trasfondo la época de la Revolución Francesa: un joven suizo marcha a París y allí se ve envuelto en el curso de los acontecimientos, en el amor y en la política ${ }^{11}$. El protagonista es un joven noble de Solothurn, Frank Zurlauben, sobrino del comandante de la guardia suiza en París. Poco antes de su muerte, su madre le ha pedido que no viaje a Francia bajo ningún concepto, pero su situación familiar - problemas con un padre excesivamente autoritario - y la insistencia del enviado francés en Solothurn le incitan a ello. Allí se enamora de la señora de Valmont de forma apasionada, pero ésta no hace caso de sus pretensiones. Será al estallar la Revolución Francesa cuando el protagonista demuestre su valía y su grandeza al hacerse pasar por el señor de Valmont y ofrecer su vida para la salvación de la mujer a la que ama, un gesto tal vez impropio de ese periodo de fin de siglo en el que se escribe la novela, pero sí propio de los personajes de Spitteler. La composición de esta obra recuerda en mucho el estilo de C. F. Meyer, no sólo por remontarse a un momento histórico del pasado, sino también por la forma en que está construida utilizando el recurso de la novela marco, aplicado por Meyer a la práctica totalidad de su producción, con lo que Spitteler rinde de nuevo un homenaje literario a otro de los grandes autores

11 El marco de la trama presenta fuertes concomitancias con Das Amulett (1873) de Conrad Ferdinand Meyer, en la que la matanza de hugonotes que tuvo lugar en París durante la famosa Noche de San Bartolomé sirve de trasfondo a las aventuras de un joven suizo protestante. 
que dieron fama a las letras de la Confederación durante el siglo XIX. Algo similar es lo que ocurre en la novela corta Friedli der Kolderi, en la que Spitteler se introduce en las técnicas de la novela rural para presentar a un protagonista campesino, mozo de labranza, que presenta rasgos fácilmente comparables con los de Uli, el protagonista de las famosas novelas de J. Gotthelf. Spitteler crea en Friedli a un personaje absolutamente real - realista sería tal vez más apropiado -, pero, a diferencia de las obras de Gotthelf, el mundo rural no aparece visto aquí desde la perspectiva del protagonista, sino desde fuera. Algo evidente, puesto que Spitteler nunca llegó a conocer el mundo del campo como lo conoció el párroco bernés, quien contaba entre sus feligreses con individuos de características muy similares a las de los protagonistas de sus novelas. Friedli es un joven mozo, malhumorado y fácilmente irascible, que, tras una disputa con su amo, se marcha de la granja. En el camino se encuentra con un compañero con el que pasa unas horas; un extranjero les pregunta por una dirección y Friedli no duda en indicársela, darle una serie de consejos y acompañarle un trecho del camino. Pero el forastero no hace caso de las indicaciones de Friedli y cae por un precipicio. Los dos jóvenes encuentran el cadáver y lo vigilan hasta el amanecer. Es en el curso de estas veinticuatro horas cuando acontece la verdadera acción de la obra: el proceso psicológico que tiene lugar en la mente de Friedli y que le hace reflexionar sobre su actitud respecto de su amo, así como sobre el valor de la vida en general. De nuevo, por tanto, un análisis psicológico que supera las descripciones del entorno rural, que no ofrecen en ningún momento la rigurosidad de su modelo, pero en los que tampoco se centraba realmente el interés de Spitteler.

Tras escribir una serie de tragedias de corte clásico, que no tuvieron ningún éxito, Jakob Burckhardt, cuyos estudios y enseñanzas le habían descubierto en realidad el mundo de la Antigüedad, le desaconsejó que siguiera por esa línea, pues él mismo consideraba que la literatura no tenía por qué ceñirse exclusivamente a los patrones clásicos. Siguiendo, por tanto, sus dictados, Spitteler compuso una colección de novelas cortas, una historia para niños y, finalmente, una obra de corte naturalista, Conrad der Leutnant. Eine Darstellung (1905), en la que intentó aplicar las formas propias de este movimiento desarrollando de manera directa la problemática padre-hijo, que él mismo tan bien conocía. Aquí, el autor hace uso de una 
refinada psicología, de una densa atmósfera psicológica de la que rodea a un protagonista capaz de destruir la armonía del "idilio" en el que vive su familia al marcharse a Viena y casarse con una joven de la ciudad, para poder dedicarse a sus inclinaciones artísticas - la música -, dando así al traste con las aspiraciones aspiraciones del padre a una vida aburguesada, pero reconocida a todos los niveles sociales. Las concomitancias con la biografía del propio Spitteler son más que llamativas ${ }^{12}$. También compuso una serie de baladas Balladen (1895) - y poemas - Gras- und Glockenlieder (1906) -.

Pero la obra más conocida de Spitteler hoy en día sigue siendo, sin duda, su novela Imago (1906), pues en ella se percibe mejor que en ninguna otra la evolución del autor en la plasmación de la relación del individuo respecto de su psique. En ella, el autor intentó dar forma literaria a su propia problemática vital como artista y a su pasión "imaginaria” (imago) por su prima Ellen Brodbeck, recurriendo para ello a una prosa en la que predomina el elemento psicológico por encima de todos los demás, puesto que el yo literario aparece magistralmente descompuesto en diversas instancias. El protagonista, el artista Viktor, regresa a una pequeña ciudad suiza tras muchos años de ausencia, y no puede evitar tener hacia todo una mirada enormemente crítica. El motivo del amor desempeña aquí también un papel fundamental: el amor real (Pseuda, la mujer a la que amara antes de marcharse, y ahora casada con otro, "falsa" y que no coincide, por tanto, con su concepción del amor, de ahí el nombre) y el amor ideal (Theuda, la que fuera verdaderamente su amor y según la que ha construido su modelo ideal), los dos con el mismo rostro, pero con diferentes expresiones. En una lucha entre ambos, triunfa el segundo, y así, dado que en el entorno sofocante de la pequeña burguesía no es capaz de continuar con su obra artística, el protagonista decide marcharse de nuevo. La calidad de la novela viene dada sobre todo por el contraste entre las descripciones de este en-

12 Es quizá en esta obra donde se ve con mayor claridad cómo la forma preocupaba al autor mucho más que el contenido. Él mismo se expresa en este sentido cuando dice: "Die schwierige Form der Darstellung wählte ich, um mir die Prosa schwer zu machen. Ein Künstler muß sich nämlich immer zugleich Aufgaben stellen”. SpitTeler, Carl, Gesammelte Werke. Ed. de Wilhelm Altwegg, Gottfried Bohnenblust y Robert Faesi. Artemis, Zúrich 1945-1958, vol. 6, 487. 
torno físico y las de las reflexiones en la mente de Viktor, dando como resultado una visión muy claramente perfilada y un tanto satírica de la realidad suiza del momento, muy en la línea de las descripciones de G. Keller en sus historias de Seldwyla: las convenciones patrióticas y el espíritu pequeñoburgués propio del entorno de la pequeña ciudad suiza son duramente criticados a través de la descripción de un protagonista que se ve obligado a luchar por su libertad en ese medio ${ }^{13}$. Es, de nuevo, el motivo de Prometeo: el contraste entre el solitario deseoso de cambiar el mundo y la masa ingente:

Nun wachte er auf, der enge Horizont entschwebte, sein Stolz erinnerte sich, und sein Gedanke verglich. Was für ein Gegensatz! Und welch ein Hohn im Gegensatz! Draussen in der Fremde: offene Arme, warme Aufnahme, gutwillige Duldung seiner Eigentümlichkeit, Nachsicht gegen seine Fehler; hier in der Heimat: engherzige Nörgelei,

13 Esta imagen de la pequeña ciudad adormecida, que vive sus días al margen del curso del mundo igual que la Seldwyla de Keller, la había plasmado ya en uno de los primeros textos en prosa, Das Wettfasten von Heimligen, en el que dos individuos que pretenden a la misma mujer deciden competir entre sí para conseguir sus favores viendo quién es capaz de ayunar durante más tiempo, y que se abre con la siguiente descripción: "Heimligen ist kein Fremdenaufenthalt. Fern von den Alpen in einer engen Talschlucht gelegen, von keinem See noch Fluss gespiegelt, arm und klein, mit einer einzigen gepflasterten Strasse, die so kurz ist, dass die Wälder von beiden Seiten bis in die Mitte hereingucken, einem kühn auf- und absteigenden Hintergässchen, wo die Hühner herumspazieren, und einem Bach, der allezeit nach etwas riecht, bietet es weder Aussicht noch Bequemlichkeit, noch Sehenswürdigkeiten. Denn die Sekundarschule, das Statthalteramt und das Postgebäude vor dem "unteren Tor" - das will sagen unterhalb des Städtchens, denn Tore hat Heimligen seit einem Jahrhundert nicht mehr -, zeichnen sich nur dadurch aus, dass sie etwas weniger baufällig erscheinen. Die Kirche aber ist an der entlegensten Stelle des Ortes hinter dem Pfarrhaus versteckt und nur dem Einheimischen mittels Fusspfaden, Brückchen und Scheunendurchgängen erreichbar. Konzerte und Theater gibt es in Heimligen auch nicht, höchstens alle Schaltjahre einmal einen Ball, von den vereinigten Geldmitteln der Feuerwehr und des gemischten Chors mühsam, nach monatelangen Unterhandlungen zustandegebracht. Dagegen fehlt es nicht an Pinten, Herbergen und Gasthöfen". Spitteler, Carl, Das Wettasten von Heimligen. En: Linsmayer, Charles (ed.), Frübling der Gegenwart. Vol. 1. Ex Libris: Zúrich 1980, 7. 
Unfehlbarkeitsdünkel, Verneinung seiner gesamten Persönlichkeit. Durch diese Vergleichung wurde alle Bitterkeit aufgerührt, die er seit sechs langen Wochen geschluckt hatte, und jäh wie er war, entbrannte er in heissem Kriegszorn. Nicht mehr schweigend dulden! zum Angriff! Ich will unter euch treten, euch die Pharisäermaske herunterreissen, euer heuchlerisches Prahlwörterbuch zerzausen. Haltet still und merket auf, was ich euch sagen will, denn ich will euch zeichnen. Seid ihr bereit? Gut, dann fange ich an. Das habe ich euch zu sagen: Eure "Tugend"? Ein Mundstück, um den Nebenmenschen zu verlästern [...]. Eure "Gemütlichkeit"? Egoismus in Heldenformat, schafwollene Oberhautanwärmung; wettert ein Unglück, hilft keins dem andern [...]. Eure Musik? O ihr jauchzendes Eiszapfen! Eure Bildung, eure Wonne über Kunst und Literatur? Wenn man euch zur Rechten die Tür zum Paradiese auftäte und zur Linken einen Vortrag über das Paradies ankündigte, ihr würdet sämtlich am Paradies vorbei in den Vortrag laufen. "Interessant, interessant!"14

Imago es, de principio a fin, el fiel reflejo de una época como no llega a serlo ninguna de sus otras obras. Y, a tenor de que se pueda criticar como una novela de características específicamente suizas debido al entorno en que se desarrolla la acción, no hay que perder de vista una serie de características que la hacen merecedora de ocupar un puesto entre las mejores obras de la literatura europea de la época: la radical enajenación del protagonista respecto de su entorno, por un lado, y la división en consciente y subconsciente, por otro, así como la alternancia entre patetismo e ironía con los que juega la voz narradora. Pero seguramente lo más significativo e interesante de la novela, por lo que a la evolución posterior de la prosa suiza se refiere, es el hecho de que presenta unidos tres elementos que serán una constante en la literatura suiza hasta nuestros días: el análisis psicológico de los personajes y la crítica social ${ }^{15}$, por un lado, y el motivo

\footnotetext{
Spitteler, Carl, Imago. En: Spitteler, Carl, Gesammelte Werke, ed. cit., vol. 4, 334 ss.

El análisis psicológico de los personajes comienza a desarrollarse ya en años inmediatamente posteriores en obras de autores como Robert Walser (18781956) o Friedrich Glauser (1896-1938), continuando hasta nuestros días en la prosa de Adolf Muschg (n. 1934) o de Urs Richle (n. 1965), por citar tan sólo a algunos de los autores más conocidos; la crítica social es una constante ya
} 
del artista que se ve obligado a huir de la estrechez física y mental del pequeño país, que Spitteler ya había tratado en Conrad der Leutnant, por otro.

Bien es cierto que el tema de la huida y el regreso a la patria está presente en la literatura suiza casi desde que puede hablarse de ésta como $\mathrm{tal}^{16}$, y que es, precisamente, uno de los rasgos que con mayor claridad permiten ver las diferencias existentes entre la literatura escrita en la Confederación y la del resto de los países de habla alemana, pues a través de él se pone de manifiesto una relación extremadamente dramática entre el individuo que hace tiempo ha dejado atrás su país y que, tras su regreso, lo percibe de una manera radicalmente diferente, con una capacidad crítica imposible de encontrar en otras latitudes. Ésta es exactamente la situación en la que se encuentra Viktor, el protagonista de Imago, un intelectual que regresa a su pequeña ciudad natal para sufrir una de las mayores decepcio-

desde el s. XIX, pero es en el XX, en la obra de los autores que comenzaron a publicar sus obras en torno a 1970, donde esta crítica adquirirá unos contornos tanto o más duros que los aquí reflejados. Sobre este tema véase mi estudio $L a$ crítica social en la nueva novela regional alemana. El modelo de Gerold Späth. Del Orto, Madrid 1998.

16 A modo de referencia menciono tan sólo algunos de los títulos más conocidos, en los que este motivo se constituye en eje central: Ulrich BRÄKER, Lebensgeschichte und Natürliche Ebentheuer des Armen Mannes im Tockenburg (1788); Jeremias GoTTHELF, Bauernspiegel (1837); Gottfried KELLER, Der grüne Heinrich (1. Fassung 1854/55; 2. Fassung 1879/80); Albert Bächtold, De goldig Schmid (1942); Jakob BüHrER, Sturm über Stifflis (1934); Meinrad IngLIN, Wendel von Eun (1925); Friedrich DÜRRENMATT, Der Besuch der alten Dame (1956); Max FrISCH, Stiller (1954); Paul NizON, Untertauchen. Protokoll einer Reise (1972); Urs WIDMER, Schweizer Geschichten (1975); Urs JAEGGI, Soulthorn (1990); Thomas Hürlimann, Der Gesandte (1991). Por otro lado no hay que olvidar tampoco que la historia de la literatura suiza cuenta con un buen número de obras en las que un individuo que regresa a Suiza ejerce de narrador, como en Der Heilige (1879) de Conrad Ferdinand Meyer o Im Sommer des Hasens (1965) de Adolf Muschg. En su ensayo "Der Traum an der Grenze. Zur literarischen Phantasie in der Schweiz", Peter von Matt explica esta actitud negativa y crítica del suizo respecto de su país como consecuencia de la experiencia de la frontera ("geprägt von der Erfahrung der Grenze"), pues la consciencia de la frontera, de los límites, de lo que ésta significa y de qué lo separa, es algo que se introduce en todos y cada uno de estos personajes, hasta el extremo de configurar de principio a fin su personalidad. Cfr. vON MATt (2001), 115 ss. 
nes de su vida en un entorno que para él más que su hogar resulta ser, en definitiva, un infierno ${ }^{17}$. La novela se convierte así en una retrospectiva de los sufrimientos vividos, presentes en los recuerdos, pero distanciados por la perspectiva del tiempo, lo que permite al autor introducir una pequeña dosis de ironía, ese rasgo tan característico también de los escritores suizos. Es una especie de balance de un alma dolida, una descripción de reflexiones y sentimientos que se anticipan a los procesos de psicoanálisis, de los que aún no se hablaba en la época, y a través de los cuales se dibuja una de las grandes constantes de la literatura del siglo XX: la destrucción del artista, del individuo con talento creativo, en el seno de la sociedad ${ }^{18}$. En Imago se ve con enorme claridad la (no) relación del artista con el entorno burgués de su ciudad natal, a la que regresa justo al comienzo de la novela, y en la que será incapaz de integrarse, tal como ocurriera ya a otros muchos protagonistas de novelas de similar trasfondo ${ }^{19}$. Y es justamente esta postura

17 Es importante tener en cuenta que Spitteler es el primero en definir en uno de los títulos de los capítulos de la novela la pequeña ciudad suiza como "Hölle der Gemütlichkeit". Esta idea de la felicidad y el bienestar visto desde fuera y del infierno como realidad vivida desde dentro ha dado lugar también a numerosas obras en la narrativa suiza. Seguramente la que recuerda de una forma más directa la obra de Spitteler es la narración Die heile Hölle (1974) de Gerold SPÄTH, en la que se describe la vida cotidiana de una familia, aparentemente armónica, en el idilio de una pequeña ciudad suiza; pero en realidad, tras la fachada de la casa lo que se esconde es un infierno en el que pasan sus días los miembros de una familia desgarrada, que no tiene nada en común y tampoco nada que decirse entre sí. Una metáfora evidente de la propia Confederación Helvética.

18 En el ámbito de la literatura de la Confederación son muy numerosas las obras que han tratado este tema. Entre ellas destacan, además de la de Spitteler, Der grüne Heinrich de Gottfried Keller, Der Landstörtzerer (1909) de Paul ILG, Pfannenstiel (1940) de Albin ZolLinger, y Stiller (1954) de Max Frisch.

19 Como es el caso, por ejemplo, de Heinrich Lee en la primera versión de Der grüne Heinrich. Malcolm Pender ve en Imago una parodia del género de la novela de formación; pero más que una parodia, lo que es realmente es un Antibildungsroman, en el sentido en que las pautas que Goethe define en su Wilhelm Meister, y que se consideran como canónicas del género, no se cumplen aquí en su totalidad, ni siquiera en el final armónico de integración en el marco social, una de las premisas fundamentales para la conclusión de un proceso de formación bien llevado a cabo. Cfr. Pender 1985: 96. 
particular del protagonista, decididamente opuesta a la norma, la que marca un punto de inflexión en la literatura suiza, al romper con los moldes predefinidos, a los que se ajustaban todas las manifestaciones literarias del momento. El protagonista de la novela, al igual que el resto de los protagonistas de las obras del autor, es un personaje problemático, en constante interacción con su entorno, en constante lucha consigo mismo por dominar su vida, una situación que no se reflejaba en novelas anteriores. No obstante, y a pesar de las novedades temáticas que puedan encontrarse en Imago, no hay que olvidar que ésta es, con mucho, la mejor obra salida de la pluma de Spitteler en lo que a adaptación de forma y contenido se refiere. El resto de sus obras no responden a esta categoría, algo que ha de tenerse muy en cuenta a la hora de llevar a cabo un estudio detallado de su obra: con excepción de Spitteler, ningún otro escritor suizo de su época fue capaz de desplegar una paleta tan amplia y diversa de variantes estilísticas, y su valor no reside, pues, tanto en el contenido como en el proceso de innovación, de elaboración formal de todos y cada uno de sus textos, una experimentación de la que se benefició, sin duda, la generación inmediatamente posterior.

En este sentido, puede establecerse una conclusión, válida seguramente para otros muchos autores helvéticos: los artistas suizos suelen ser con frecuencia innovadores y creadores de nuevos estilos, pero, en su mayoría, lo hacen al margen de las corrientes de la época. Spitteler pertenece a este grupo de innovadores que temáticamente abren caminos muy nuevos, pero que, formalmente, siguen manteniendo posturas conservadoras, contracorriente. Su obra presenta, precisamente por ello, ciertas debilidades de carácter estético, pero la dimensión psicológica que domina toda su producción merece que sus obras en prosa sean revisadas de nuevo y analizadas en función de la narrativa escrita en la Confederación con posterioridad. Si esto se lleva a cabo, sucederá seguramente lo mismo que ha sucedido ya con autores como Robert Walser o Ludwig Hohl, olvidados durante largos años y recuperados ahora como grandes nombres de las letras suizas. En esta recuperación queda aún un largo camino por recorrer al inicio del cual se encuentra precisamente la figura de Carl Spitteler. 


\section{Referencias bibliográficas}

Burkhard, Marianne. "Blick in die Tiefe: Spittelers Epos Prometheus und Epimetheus". En: Burkhard, Marianne / Labroisse, Gerd (eds.), Zur Literatur der deutschsprachigen Schweiz, Ámsterdam, Rodopi 1979, 111-130 (=Amsterdamer Beiträge zur neueren Germanistik 9).

Calgari, Guido. "Carl Spitteler und die Auflehnung gegen die bürgerliche Welt”. En: Calgari, Guido, Die vier Literaturen der Schweiæ, Olten, Walter 1966, 178-186. [Trad. del italiano de Erika Tobler]

Fiorentino, Francesco. La letteratura della Svizzera tedesca. Roma, Carocci 2001.

GÜNTHER, Werner. “Carl Spitteler”. En: GÜNTHER, Werner, Dichter der neueren Schweiz I, Berna / Múnich, Francke 1963, 228-280.

GüNTHER, Werner. „Carl Spitteler“. En: Natan, Alex, Swiss Men of Letters: Twelve Literary Essays, Londres, Wolff 1970, 193-212.

McHaffie, Margareth / Ritchie, J.M. „Narrative Technique in Spitteler's Conrad der Leutnant‘. En: German Life and Letters 14 (1961), 45-51.

McHAfFie, Margareth. "Prometheus and Viktor: Carl Spitteler's Imago". En: German Life and Letters 31 (1977), 67-77.

Paoli, Rodolfo. "Die literarische Gestalt Carl Spittelers". En: Literaturwissenschaftliches Jabrbuch im Auftrag der Görres-Gesellschaft 13 (1972), 307-329.

Pender, Malcolm. "From Imago to Stiller: Aspects of the German-Swiss 'Künstlerroman”'. En: Flood, John L. (ed.), Modern Swiss Literature. Unity and Diversity, London, Oswald Wolff 1985, 93-109.

Peuckert, Will-Erich. “Carl Spitteler”. En: Zeitschrift für deutsche Philologie 80 (1961), 142-147.

QuATtrocchi, Luigi. “Carl Spitteler sulla traccia dell' 'unico' romanzo”. En: Annali Istituto Universitario Orientale (Napoli, Sezione Germanica) 10 (1967), 87-105.

Quattrocchi, Luigi. Spitteler narratore. Roma, Edizioni dell'Ateneo 1968.

SCHARF, Roger. Carl Spitteler (1845-1924) und die Anfänge der modernen Kusnt in der Schweiz. Berna, Peter Lang 1999. 
Schmidt-Henkel, Gerhard. "Mythos und Mythologie in Carl Spittelers Olympischem Frübling". En: Koopmann, Helmut, Mythos und Mythologie in der Literatur des 19. Jahrbunderts, Frankfurt, Klostermann 1979, 307-320.

STAUfFaCHER, Werner. Klassiker der Kritik: Carl Spitteler. Zúrich, Artemis 1965.

StAuffacher, Werner. "Carl Spittelers Blutenfee: Zur Wirkungsweise literarische Einflusskonstellationen”. En: Jost, François (ed.), Proceedings of the IV th Congress of the International Comparative Literature Association, La Haya, Mouton 1966, vol. II, 888-896.

Stauffacher, Werner. "Carl Spitteler". En: Kohlschmidt, Werner, Bürgerlichkeit und Unbürgerlichkeit in der Literatur der deutschen Schweiz, Berna, Francke 1978, 83-98.

StAuffacher, Werner. "Der Verweigerer und seine Partner - 1880 und 1950. Von Carl Spittelers »Prometheus und Epimetheus« zu Max Frischs »Stiller«". En: Grotzer, Peter (ed.), Aspekte der Verweigerung in der neueren Literatur aus der Schweiz, Zúrich, Amman 1988, 39-53.

von Matt, Peter. "Der Traum an der Grenze. Zur literarischen Phantasie in der Schweiz". En: von Matт, Peter, Die tintenblanen Eidgenossen. Über die literarische und politische Schweiz, Múnich, Hanser 2001, 113-122.

Wetzel, Justus Hermann. Carl Spitteler. Ein Lebens- und Schaffensbericht. Berna / Múnich, Francke 1973.

Witz, Friedrich (ed.). Carl Spitteler. Zum 100. Geburtstag. Zúrich, Artemis 1945. 